\title{
Curso de información electrónica del Patrimonio Histórico
}

El acercamiento y conocimiento de la información aplicada al Patrimonio Histórico se plantea como una necesidad de formación dentro del campo de la documentación e información, ya que los cursos generalistas, si bien cumplen una función de formación básica, necesitan la complementariedad de cursos de documentación especializada en las distintas materias. En esta línea se planteó la organización de un curso especializado sobre distintos aspectos de la documentación e información electrónica en la temática del Patrimonio Histórico, para la formación de los profesionales de la documentación, así como de los profesionales del Patrimonio Histórico, en las técnicas y recursos informativos aplicados a este ámbito temático.

El Instituto Andaluz del Patrimonio Histórico $(\mathrm{IAPH})$ en colaboración con la Asociación Andaluza de Documentalistas (AAD) ha celebrado en la sede de la Universidad Internacional de Andalucía (Conjunto Monumental de la Cartuja, Sevilla) durante los días 12, 13 y 14 de mayo de 1999 un curso sobre la información electrónica aplicada al ámbito del patrimonio histórico, bajo la dirección y coordinación de Nieves González Fernández-Villavicencio, en representación de la $A A D$, y de Isabel Ortega Vaquero, en representación del IAPH.

La primera jornada de trabajo se inició con la intervención de Antonio Rodríguez de las Heras, profesor de la Universidad Carlos III de Madrid, sobre los principales aspectos y propiedades que caracterizan el espacio digital. Ello, sirvió de marco de referencia sobre las posibilidades y dificultades que nos presenta este nuevo mundo digital.

A partir de esta primera inmersión en el nuevo mundo de la información que hoy nos ha tocado vivir, se presentaron diferentes experiencias que tienen como denominador común el desarrollo de información electrónica aplicada al conocimiento y difusión del patrimonio histórico. En este sentido se presentaron las líneas actuales de trabajo y los proyectos de futuro en torno a la información electrónica y multimedia del Sistema de Información del Patrimonio Histórico de Andalucía (SIPHA) desarrollado por el Centro de Documentación del IAPH, a cargo de Susana Limón Rodríguez. Asimismo, la presentación de El Legado Andalusí, a cargo de Inmaculada Cortés, ofreció una nueva visión sobre la recuperación y difusión del patrimonio histórico, a través del desarrollo del itine- rario de almorávides y almohades en la web de esta fundación. Por último, José María Martínez Sánchez (Grupo de Tratamiento de Imágenes de la Universidad Politécnica de Madrid) presentó diversos proyectos en el acceso a bases de datos de museos, bibliotecas y archivos, materializados actualmente en el proyecto Babel disponible en la web.

Además de la presentación de experiencias, intentamos ofrecer la visión de otros sectores implicados en el desarrollo de la información electrónica del patrimonio histórico, desde las líneas de política cultural al apoyo del sector empresarial, así como propuestas de nuevos ámbitos de aplicación. En este sentido, Carmen Caro, secretaria del Punto Focal Español del Programa de Bibliotecas de la Comisión Europea, expuso los programas de la Comisión Europea para la participación de archivos, bibliotecas y museos en el desarrollo de la Sociedad de la Información. Por otro lado, se planteó la relación, posibilidades y ofertas que la empresa puede ofrecer en la difusión del patrimonio histórico, a través de la elaboración de productos multimedia y páginas web, a cargo de Eva $M^{a}$ Sánchez de la empresa Crea! Multimedia. Por último, se estableció una propuesta para la creación de la Biblioteca Digital del Patrimonio Histórico, mediante la integración de los recursos de información en el ámbito patrimonial para un acceso fácil de los usuarios, por parte de Nieves González e Isabel Ortega.

En la última jornada tuvo lugar la presentación de productos multimedia para la difusión del patrimonio cultural en la era hipermedia, por Arturo Colorado Castellary, profesor de la Universidad Complutense de Madrid. Mostró, a través de diferentes CdRoms sobre museos y obras de arte, la rápida evolución de las técnicas aplicadas a la difusión patrimonial, de lo multimedia a lo hipermedia.

Como cierre de este curso, y a modo de conclusión, se celebró un Foro-Debate en torno a las necesidades de información de los profesionales en este nuevo entorno cultural que supone las tecnologías de la información y las comunicaciones, con la participación de Arturo Colorado Castellary, Elvira Ordoñez (Biblioteca de la ETSA de la Universidad de Sevilla), Eva Ma Sánchez, Luis Martínez Montiel (Centro de Documentación del (APH), e Isabel Ortega Vaquero. E debate versó sobre las carencias que hoy presenta la información electrónica como medio de conocimiento del patrimonio histórico, las expectativas y necesidades que tienen planteadas los profesionales y usuarios, y las líneas y perspectivas de futuro que nos ofrece este nuevo medio en relación al conocimiento y al acercamiento del patrimonio histórico a la sociedad.

En cuanto a la asistencia, el curso ha contado con un total de 24 alumnos, procedentes principalmente del ámbito de la documentación y la biblioteconomía, y en menor medida del ámbito patrimonial. En cuanto a la procedencia geográfica, en su mayoría, procedían de diferentes provincias andaluzas, principalmente Sevilla, Córdoba y Granada, así como de otras Comunidades Autónomas como de la CA. de Aragón.

De acuerdo con el desarrollo y resultados obtenidos, el IAPH y la AAD ha organizado para marzo del año próximo en Baeza la segunda edición del Curso de Información Electrónica del Patrimonio Histórico.

Para una mayor información acerca de los proyectos y temas tratados en este curso, se relacionan las siguientes direcciones Web:

\section{- El Legado Andalusí: http://www.legadoandalusi.es/}

- El Centro de Documentación del IAPH: http://www.iaph.junta-andalucia.es/documentacion.htm

- Proyecto Babel (Servicios Multimedia para Museos y Bibliotecas vía Internet): http://www.gti.ssr.upm.es./projs/babel.html

- Punto Focal Español del Programa de Bibliotecas de la Comisión Europea: http://www.bne.es/esp/punto.htm

Isabel Ortega Vaquero. Centro de Documentación del IAPH 